\title{
Serious adverse events and 30-day hospital readmission rate following elective total knee arthroplasty: a systematic review and meta-analysis
}

\author{
Costas Papakostidis ${ }^{1}$, Peter V. Giannoudis ${ }^{2,3}$, J. Tracy Watson ${ }^{4}$, Robert Zura ${ }^{5}$ and R. Grant Steen ${ }^{5,6^{*}}$ (B)
}

\begin{abstract}
Background: Elective total knee arthroplasty (TKA) is a common surgery which has evolved rapidly. However, there are no recent large systematic reviews of serious adverse event (SAE) rate and 30-day readmission rate (30-dRR) or an indication of whether surgical methods have improved.

Methods: To obtain a pooled estimate of SAE rate and 30-dRR following TKA, we searched Medline, Web of Science, Cochrane Library, and Google Scholar databases. Data were extracted by two authors following PRISMA guidelines. Eligibility criteria were defined prior to a comprehensive search. Studies were eligible if they were published in 2007 or later, described sequelae of TKA with patient $N>1000$, and the SAE or 30-dRR rate could be calculated. SAEs included return to operating room, death or coma, venous thromboembolism (VTE), deep infection or sepsis, myocardial infarction, heart failure or cardiac arrest, stroke or cerebrovascular accident, or pneumonia.

Results: Of 248 references reviewed, 28 are included, involving 10,153,503 patients; this includes 9,483,387 patients with primary TKA (pTKA), and 670,116 patients with revision TKA (rTKA). For pTKA, the SAE rate was 5.7\% (95\% Cl 4.4 $\left.-7.2 \%, I^{2}=100 \%\right)$, and the $30-\mathrm{dRR}$ was $4.8 \%\left(95 \% \mathrm{Cl} 4.3-5.4 \%, I^{2}=100 \%\right)$. For rTKA, the SAE rate was $8.5 \%(95 \% \mathrm{Cl}$ $\left.8.3-8.7 \%, I^{2}=77 \%\right)$, while the 30 -dRR was $7.2 \%\left(95 \% \mathrm{Cl} 6.4-8.0 \%, I^{2}=81 \%\right)$. Odds of 30-dRR following pTKA were about half that of rTKA (OR $\left.0.57,95 \% \mathrm{Cl} 0.53-0.62 \%, p<0.001, P^{2}=45 \%\right)$. Of patients who received pTKA, the commonest SAEs were VTE (1.22\%; 95\% Cl 0.83-1.70\%) and genitourinary complications including renal insufficiency or renal failure (1.22\%; $95 \% \mathrm{Cl} 0.83-1.67 \%)$. There has been significant improvement in SAE rate and 30-dRR since 2010 ( $X^{2}$ test $\left.<0.001\right)$.
\end{abstract}

Conclusions: TKA procedures have a relatively low complication rate, and there has been a significant improvement in SAE rate and 30-dRR over the past decade.

Keywords: Return to surgery, Venous thromboembolism, Infection

\footnotetext{
*Correspondence: G_Steen_MediCC@yahoo.com

${ }^{5}$ Department of Orthopedic Surgery, Louisiana State University Medical

Center, New Orleans, LA, USA

${ }^{6}$ Present address: 103 Van Doren Place, Chapel Hill, NC 27517, USA

Full list of author information is available at the end of the article
}

(c) The Author(s). 2021 Open Access This article is licensed under a Creative Commons Attribution 4.0 International License, which permits use, sharing, adaptation, distribution and reproduction in any medium or format, as long as you give appropriate credit to the original author(s) and the source, provide a link to the Creative Commons licence, and indicate if changes were made. The images or other third party material in this article are included in the article's Creative Commons licence, unless indicated otherwise in a credit line to the material. If material is not included in the article's Creative Commons licence and your intended use is not permitted by statutory regulation or exceeds the permitted use, you will need to obtain permission directly from the copyright holder. To view a copy of this licence, visit http://creativecommons.org/licenses/by/4.0/. The Creative Commons Public Domain Dedication waiver (http://creativecommons.org/publicdomain/zero/1.0/) applies to the data made available in this article, unless otherwise stated in a credit line to the data. 


\section{Introduction}

Serious adverse events (SAEs) can be an indicator of therapeutic failure or declining patient health and are costly to the medical system [1]. Because SAEs represent an opportunity to improve patient medical care [2], reimbursement policies emphasize reducing the SAE rate associated with specific medical facilities and defined medical services [3]. The Affordable Care Act in the USA mandated reporting of SAEs and established the 30-day readmission rate (30-dRR) as an important metric [4]. Hospital 30-dRR is now widely used as a surrogate measure of healthcare quality by the Centers for Medicare \& Medicaid Services [5]. The emphasis on characterizing healthcare quality has resulted in a spate of recent papers that have assessed the SAE rate and the 30-dRR for total knee arthroplasty, although these analyses often include fewer than 10,000 patients [6-8].

There is heterogeneity in the reported complication rate associated with total knee arthroplasty (TKA), which may arise because of the relatively small samples studied. For example, using the American College of Surgeons National Surgical Quality Improvement Program (NSQIP) database for primary total knee arthroplasty (pTKA) for the years from 2011 to 2013, the SAE rate was $1.4 \%$ among 65,694 patients [6], while the 30 $\mathrm{dRR}$ was $3.5 \%$ among 6790 patients [7]. As for revision total knee arthroplasty (rTKA), again using the NSQIP database from 2011 to 2013, the rate of SAEs was $2.7 \%$ among 4911 patients [6], while the 30-dRR was $6.4 \%$ among 4977 patients [8]. Several factors could impact these metrics, including the era in which TKA was done, procedural complexity, medical comorbidities, and patient age, so small sample sizes can yield unstable estimates.

Current literature lacks a large systematic review of the serious adverse event (SAE) rate and the 30-day readmission rate (30-dRR) for TKA. Our primary aim is to provide a pooled estimate of effect size for both SAE rate and 30-dRR following elective TKA. Secondary aims of this systematic review are to evaluate causes of and risk factors for SAEs and 30-dRR, and to determine whether there have been recent reductions in SAE rate or 30dRR.

\section{Methods}

This systematic review and meta-analysis adhered to the Preferred Reporting Items for Systematic Reviews and Meta-Analyses (PRISMA) guidelines [9].

\section{Eligibility criteria and literature search}

Eligibility criteria were defined prior to a comprehensive search of the relevant literature and were formulated according to the PICO format. Studies were considered eligible if they met the following inclusion criteria:
- Participants - Adult patients derived from large cohort studies including at least 1000 patients and published in 2007 or later

- Intervention - Primary total knee arthroplasty (pTKA) (unilateral or bilateral) or revision total knee arthroplasty (rTKA)

- Comparator - Comparison, when possible, between various subgroups of an index cohort

- Outcome - Serious adverse event (SAE) rate within 30 days following the surgical procedure and 30-day hospital readmission rate (30-dRR). SAEs included the following conditions: return to the operating room (OR), death or coma, venous thromboembolism (VTE), deep infection or sepsis, myocardial infarction (MI), heart failure (HF) or cardiac arrest, stroke or cerebrovascular accident, or pneumonia. A "30-day readmission" was defined as an admission to any service of any hospital within 30 days of a TKA procedure or discharge from an orthopedic service following a TKA procedure.

Exclusion criteria were studies reporting strictly on a subgroup of adverse events (e.g., mortality rate, MI rate following TKA, etc.), studies with inadequate data for both outcomes of interest, studies published prior to 2007, studies with less than 1000 participants, and experimental or biomechanical studies.

An electronic search of the Medline database via the PubMed search engine was initially conducted by two independent researchers (CP, RGS) using the following Medical Subject Headings (MeSH) terms and Boolean operators: (total knee arthroplasty OR total knee replacement) AND (thirty day OR 30

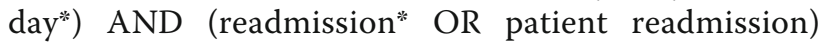
AND (complication* OR adverse event OR outcome* ${ }^{*}$. The search was further extended to the Web of Science, Cochrane Library, and Google Scholar databases. In addition, the reference sections of all eligible articles discovered in the initial electronic search were then manually searched, as was the reference section of a recent meta-analysis [3], to yield articles that had been potentially missed by the initial search. No language restrictions were imposed. Titles of journals, names of authors, and institutions were not masked, to avoid duplication of data. The reviewers independently assessed the titles and abstracts of all retrieved articles and, for potentially eligible articles, the full text was obtained and screened against the eligibility criteria. Any disagreement between the reviewers was resolved by discussion. The search was completed on February 21, 2020 and was limited to the time period since 1 January 2007. 


\section{Data extraction}

The following data were extracted from each eligible paper and tabulated into a predefined spreadsheet: demographic data and baseline characteristics, sample size, data source, enrollment period, type of procedure (pTKA, rTKA), number of SAEs, number of hospital readmissions within 30 days, and causes and risk factors for 30-day readmissions or SAEs. The data source was categorized as single hospital database, multicenter registry database (collecting data from more than two hospitals), and nationwide databases (Veteran Affairs [VA], Center for Medicare and Medicaid Services [CMS], National Surgical Quality Improvement Program [NSQUIP]). Patients' enrollment was categorized into two periods: before 2010 and after 2010. Risk factors for the primary outcomes of interest were recorded from relevant studies when available, along with the respective statistical correlation based on multivariate analysis. Causes for 30-day readmissions and SAEs were collected from relevant studies and pooled appropriately (as described in the statistical section).

\section{Assessment of the risk of bias}

Risk of bias was evaluated across all primary studies using the Quality in Prognosis Studies (QUIPS) tool [10]. The overall risk of bias was ascertained by rating each of the six component domains of the tool, namely (1) study participation, (2) attrition, (3) prognostic factor measurement, (4) outcome measurement, (5) confounding, and (6) statistical analysis and reporting. For every primary study, each domain of the QUIPS tool was given a rating of either low, moderate, or high risk of bias, based on certain prompting items and considerations provided by the tool.

Each risk factor for the main outcomes of interest was assessed in terms of quality of evidence based on the adjusted Grading of Recommendations Assessment, Development and Evaluation (GRADE) framework [11]. The GRADE framework provides 7 factors, each one being rated as either "no serious limitations" or "serious limitations". A risk factor that had 5 or more scores of "no serious limitations" were considered high quality. Those with 3 or 4 scores of "no serious limitations" were considered "moderate quality", while risk factors with less than 3 scores of "no serious limitations" were defined as low quality.

\section{Statistical analysis}

All outcomes of interest obtained from studies without a comparator cohort were expressed as proportions (e.g., SAE rate or 30-dRR). Pooling of proportions was done with the MedCalc software (version 14.8.1) using a random effects model, as we assumed that the cohorts within the primary studies were not identical, so the true effect size was not the same across those studies. Statistical heterogeneity was detected with the use of Cochran's Q test and Higgins $\mathrm{I}^{2}$ test $[12,13]$. The level of statistical significance was set at 0.1 for the $\mathrm{Q}$ test (as it is characterized by low sensitivity for detecting heterogeneity). The $\mathrm{I}^{2}$ test is bound at its upper end by $100 \%$ and values of 25,50 , and $75 \%$ were thought to represent low, moderate, and high degrees of heterogeneity, respectively. Only in the complete absence of statistical heterogeneity $\left(I^{2}=0\right)$ would results of the pooling process using the fixed effect model be valid. Comparison between proportions was done with the $\chi^{2}$ test.

For studies with comparator cohorts, binary outcomes of interest were expressed as odds ratios (ORs) with respective 95\% confidence intervals (95\% CIs). Pooling of data was done with the RevMan (5.3) software (Review Manager, Nordic Cochrane Centre, Copenhagen, Denmark) using the Inverse Variance statistical method and a fixed or random effects model, based on our previous assumptions. The results of pooling were expressed graphically as forest plots. In addition, appropriate funnel plots were generated to investigate the potential presence of publication bias. We utilized the Comprehensive Meta-analysis V3 software (Biostat) to generate the respective funnel plot for the 30-dRR. Furthermore, the Duval and Tweedie's Trim and Fill test was used to impute potentially missing studies, as well as Orwin's fail-safe $\mathrm{N}$ for a quantitative measurement of the publication bias. For binary outcomes based on studies with comparator groups, the RevMan 5.3 software was used to generate inverse funnel plots.

Subgroup analysis In order to explore the effect of the potential presence of heterogeneity on the final outcomes, certain subgroups of the initial cohort were determined, and the outcomes of interest were calculated within each subgroup. These subgroups were revision knee arthroplasties, unilateral knee arthroplasties, and bilateral knee arthroplasties.

\section{Sensitivity analysis}

Sensitivity analysis was performed by repeating the pooling process after eliminating studies of very large size, that would potentially affect the final outcomes by being overly weighted, and studies with a low rating by the QUIPS tool.

\section{Results}

The initial PubMed search yielded 244 citations. Three additional records were identified through the electronic search of other electronic databases, while 4 records were found through a manual search of relevant bibliographies. After duplicates were removed, 248 abstracts and abstract titles were screened for suitability. Most 
Table 1 Evidentiary table

\begin{tabular}{|c|c|c|c|c|c|c|c|c|}
\hline \multicolumn{2}{|c|}{ Author [refs] } & \multirow{3}{*}{$\begin{array}{l}\text { Publication } \\
\text { J Arthro, } 2020\end{array}$} & \multirow{3}{*}{$\begin{array}{l}\text { Procedure } \\
\text { Primary TKR } \\
\text { Rev TKA }\end{array}$} & \multirow{3}{*}{$\begin{array}{l}\text { Data source } \\
\text { Regional database, Ontario, } \\
\text { Can (IC/ES) }\end{array}$} & \multirow{3}{*}{$\begin{array}{l}\begin{array}{l}\text { Enroll-ment } \\
\text { period }\end{array} \\
2003-2016\end{array}$} & \multirow{2}{*}{$\begin{array}{l}\begin{array}{l}\text { No. of } \\
\text { patients }\end{array} \\
200,421\end{array}$} & \multirow{2}{*}{$\begin{array}{l}\text { SAEs } \\
\text { NR }\end{array}$} & \multirow{2}{*}{$\begin{array}{l}\text { 30-day } \\
\text { RR } \\
6819\end{array}$} \\
\hline 1 & Ross TD [14] & & & & & & & \\
\hline & & & & & & 4731 & NR & 289 \\
\hline 2 & $\begin{array}{l}\text { Lehtonen EJ } \\
\text { [15] }\end{array}$ & Acta Orthop Bras 2018 & Primary TKR & ACS-NSQIP & $2012-2015$ & 137,209 & 6143 & 4668 \\
\hline \multirow[t]{3}{*}{3} & Ali AM [16] & J Arthro 2018 & Primary TKR & HES & 2006-2015 & 566,323 & NR & 35,252 \\
\hline & & & Unicomp & & & 40,650 & NR & 1424 \\
\hline & & & PF & & & 11,442 & NR & 519 \\
\hline 4 & Bottle A [17] & J Arthro 2018 & Primary TKR & HES & $\begin{array}{l}\text { Apr } 2010 \\
\text {-March } 2015\end{array}$ & 311,033 & $N R$ & 18,814 \\
\hline 5 & $\begin{array}{l}\text { D'Apuzzo } \\
\text { [18] }\end{array}$ & JBJS Am 2017 & Primary TKR & SPARCS & 1997-2014 & 377,705 & NR & 22,076 \\
\hline 6 & Yao DH [19] & J Arthro. 2017 & Primary TKA & NSQIP & $2011-2014$ & 71,293 & 2490 & 1952 \\
\hline 7 & Keswani A [8] & J Arthro. 2016 & Rev TKA & NSQIP & $2011-2013$ & 4977 & 397 & NR \\
\hline 8 & $\begin{array}{l}\text { Belmont PJ } \\
{[20]}\end{array}$ & $\begin{array}{l}\text { Knee Surg Sports Traumatol } \\
\text { Arthrosc. } 2016\end{array}$ & Rev TKA & NSQIP & $2011-2012$ & 1754 & NR & 108 \\
\hline \multirow[t]{2}{*}{9} & Hart A [7] & & Bilat TKA & NSQIP & $2011-2013$ & 1771 & 67 & 64 \\
\hline & & J Arthro 2016 & Unilat TKA & & & 6790 & 151 & 240 \\
\hline \multirow[t]{2}{*}{10} & Bohl DD [6] & J Arthro. 2016 & Primary TKA & NSQIP & $2011-2013$ & 65,694 & 920 & 2956 \\
\hline & & & Rev TKA & & & 4911 & 133 & 363 \\
\hline 11 & Culler SD [21] & J Arthro, 2015 & Primary TKA & MedPAR & 2011 & 353,650 & $\begin{array}{l}41 \\
792\end{array}$ & NR \\
\hline 12 & $\begin{array}{l}\text { Raines BT } \\
\text { [22] }\end{array}$ & J Arthro 2015 & Primary TKA & VA & $2005-2009$ & 16,808 & 1848 & 1106 \\
\hline \multirow[t]{2}{*}{13} & Schairer WW & CORR 2014 & Primary TKA & Single-institution database & 2005-2011 & 1032 & NR & 64 \\
\hline & & & Rev TKA & & & 262 & NR & 34 \\
\hline \multirow[t]{2}{*}{14} & Bosco JA [24] & J Arthro 2014 & Primary TKA & Single-hospital database & 2009-2012 & 1263 & NR & 55 \\
\hline & & & Rev TKA & & & 118 & $N R$ & 14 \\
\hline 15 & $\begin{array}{l}\text { Belmont PJ Jr } \\
\text { [25] }\end{array}$ & JBJS Am, 2014 & Primary TKA & NSQIP & 2006-2010 & 15,321 & 851 & NR \\
\hline 16 & $\begin{array}{l}\text { Pugely AJ } \\
\text { [26] }\end{array}$ & J Arthro, 2013 & Primary TKA & NSQIP & 2011 & 11,814 & NR & 543 \\
\hline 17 & $\begin{array}{l}\text { Zmistowski B } \\
{[27]}\end{array}$ & JBJS Am 2013 & Primary TKA & $\begin{array}{l}\text { Institutional Arthroplasty } \\
\text { database }\end{array}$ & 2004-2008 & 5207 & NR & 199 \\
\hline 18 & $\begin{array}{l}\text { Pugely AJ } \\
{[28]}\end{array}$ & JBJS Am 2013 & Primary TKA & NSQIP & 2005-2010 & 14,052 & 1636 & NR \\
\hline \multirow[t]{2}{*}{19} & Cram P [29] & JAMA. 2012 & $\begin{array}{l}\text { Primary vs } \\
\text { Rev TKA }\end{array}$ & CMS & $1991-2010$ & $3,271,851$ & $\begin{array}{l}135 \\
195\end{array}$ & 145,504 \\
\hline & & & & & & 318,563 & $\begin{array}{l}27 \\
569\end{array}$ & 23,074 \\
\hline 20 & Cram P [30] & Mayo Clin Proc. 2012 & Primary TKA & CMS & 2006 & 64,712 & 5357 & 5320 \\
\hline 21 & $\begin{array}{l}\text { Vorhies JS } \\
\text { [31] }\end{array}$ & CORR 2012 & Primary TKA & Medicare & $2002-2007$ & 4057 & NR & 228 \\
\hline \multirow[t]{2}{*}{22} & \multirow{2}{*}{$\begin{array}{l}\text { Brown NM } \\
\text { [32] }\end{array}$} & \multirow[t]{2}{*}{ J Arthro. 2012} & Unicomp & \multirow{2}{*}{$\begin{array}{l}\text { 3-Institution database } \\
\text { (Multicenter) }\end{array}$} & \multirow[t]{2}{*}{ 2004-2009 } & 605 & 26 & 16 \\
\hline & & & Primary TKA & & & 2235 & 246 & 94 \\
\hline 23 & Singh JA [33] & Arthritis Rheum. 2011 & Primary TKA & $\begin{array}{l}\text { Regional database, } \\
\text { Pennsylvania (PHC4) }\end{array}$ & 2002 & 19,418 & 364 & NR \\
\hline 24 & Husni ME [34] & BMC Musculoskel Disord. 2010 & Primary TKA & CMS & 2000 & 9157 & 390 & NR \\
\hline 25 & $\begin{array}{l}\text { Huddleston } \\
\text { JI [35] }\end{array}$ & J Arthro, 2009 & Primary TKA & Medicare & $2002-2004$ & 2033 & 132 & NR \\
\hline
\end{tabular}


Table 1 Evidentiary table (Continued)

\begin{tabular}{|c|c|c|c|c|c|c|c|c|}
\hline \multicolumn{2}{|c|}{ Author [refs] } & \multirow{3}{*}{$\begin{array}{l}\text { Publication } \\
\text { J Arthro, } 2008\end{array}$} & \multirow{2}{*}{$\begin{array}{l}\text { Procedure } \\
\text { Primary TKA }\end{array}$} & \multirow{2}{*}{$\begin{array}{l}\text { Data source } \\
\text { Single-institution database }\end{array}$} & \multirow{3}{*}{$\begin{array}{l}\begin{array}{l}\text { Enroll-ment } \\
\text { period }\end{array} \\
\text { Jan 2000-Aug } \\
2006\end{array}$} & \multirow{2}{*}{$\begin{array}{l}\begin{array}{l}\text { No. of } \\
\text { patients }\end{array} \\
5173\end{array}$} & \multirow{2}{*}{\begin{tabular}{|l} 
SAEs \\
303
\end{tabular}} & \multirow{2}{*}{$\begin{array}{l}\text { 30-day } \\
\text { RR } \\
N R\end{array}$} \\
\hline 26 & Pulido L [36] & & & & & & & \\
\hline & & & Rev TKA & & & 645 & 61 & NR \\
\hline \multirow[t]{3}{*}{27} & $\begin{array}{l}\text { Memtsoudis } \\
\text { S [37] }\end{array}$ & CORR, 2008 & Unilat TKA & NHDS (nationwide database) & 1990-2004 & $3,672,247$ & $\begin{array}{l}299 \\
526\end{array}$ & NR \\
\hline & & & Bilat TKA & & & 153,259 & $\begin{array}{l}18 \\
696\end{array}$ & NR \\
\hline & & & Rev TKA & & & 334,155 & $\begin{array}{l}29 \\
007\end{array}$ & NR \\
\hline 28 & Katz JN [38] & Med Care. 2008 & Primary TKA & Medicare & 2000 & 80,604 & 2826 & NR \\
\hline
\end{tabular}

ACS-NSQIP, American College of Surgeons National Surgical Quality Improvement Program; CMS, Centers for Medicare \& Medicaid Services; HES, Hospital Episode Statistics; IC/ES, Institute for Clinical and Evaluative Sciences; MedPAR, Medicare Provider Analysis and Review; NHDS, National Hospital Discharge Survey; NR, not reported; PF, patellofemoral; SPARCS, Statewide Planning and Research Cooperative System; VA, Veteran's Administration

studies (187) were excluded based on information provided in the title and abstract. Sixty-one articles were ultimately retrieved for full-text review. After applying eligibility criteria, 33 articles were excluded, leaving 28 primary studies $[6-8,14-38]$ for analysis (Table 1), as summarized in a PRISMA flow chart (Fig. 1, see also PRISMA checklist, additional file).
The total number of included patients across all primary studies was $10,153,503$. Of this total, 9,483,387 patients had undergone primary TKA (pTKA), while the remaining 670,116 patients had undergone revision TKA (rTKA). Four studies used data from a single hospital database [23, 24, 27, 36], 1 study was a multicenter registry database [32], and the remaining 23 studies used

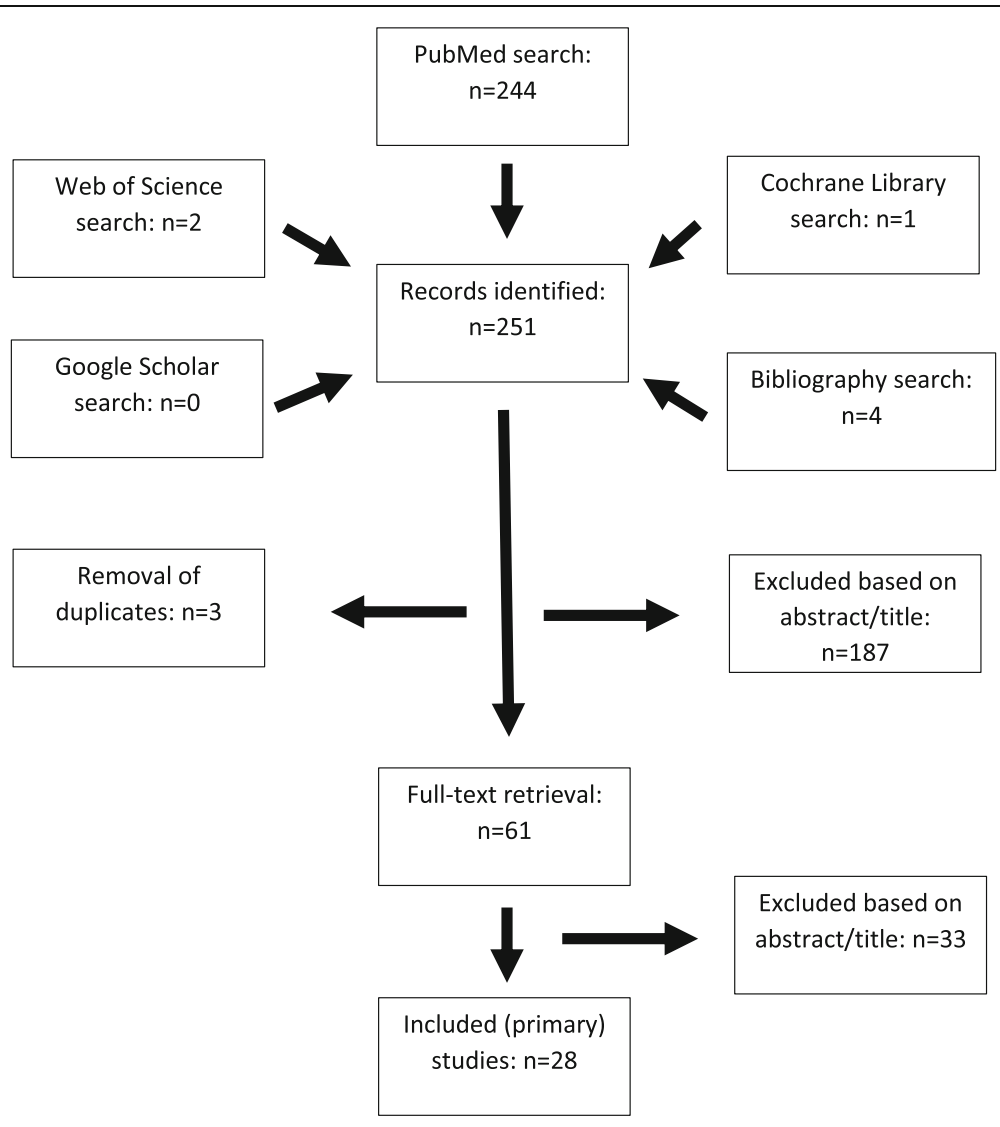

Fig. 1 PRISMA flow chart of literature review 
nationwide databases [14-22, 24-26, 28-31, 33-38] (Table 1). Eighteen studies did not include any comparator group, reporting solely on either pTKAs (16 studies) $[15,17-19,21,22,25-28,30,31,33-35,38]$ or rTKAs (2 studies) $[8,20]$. The remaining 10 studies included various comparator cohorts (pTKAs vs. rTKAs in 7 studies [6, 14, 23, 24, 29, 36, 37], unilateral versus simultaneously bilateral TKAs in 2 studies [7, 37], and unicompartmental versus pTKAs in 2 studies $[16,32]$ (Table 1).

\section{Assessment of the risk of bias}

Using the QUIPS tool, all studies were rated as having "low risk of bias" in the study participation domain, while in the remaining domains, studies were assigned scores of low, moderate, or high risk of bias (Table 2).

\section{Publication bias}

We utilized the CMA V3 (Biostat) software to produce a funnel plot for the 30-dRR data. The distribution of data points was almost symmetrical around the calculated

Table 2 The QUIPS tool

\begin{tabular}{|c|c|c|c|c|c|c|c|}
\hline \multicolumn{2}{|c|}{ Author } & \multicolumn{6}{|c|}{ Risk in the various QUIPS domains } \\
\hline & & $\begin{array}{l}\text { Study } \\
\text { participation }\end{array}$ & Attrition & $\begin{array}{l}\text { Prognostic factor } \\
\text { measurement }\end{array}$ & $\begin{array}{l}\text { Outcome } \\
\text { measurement }\end{array}$ & $\begin{array}{l}\text { Study } \\
\text { confounding }\end{array}$ & $\begin{array}{l}\text { Statistical analysis \& } \\
\text { reporting }\end{array}$ \\
\hline 1 & Ross TD [14] & Low & Low & Low & Low & Low & Low \\
\hline 2 & $\begin{array}{l}\text { Lehtonen EJ } \\
\text { [15] }\end{array}$ & Low & Low & Low & Moderate & Low & Moderate \\
\hline 3 & Ali AM [16] & Low & Low & Low & Low & Low & Low \\
\hline 4 & Bottle A [17] & Low & Low & Moderate & Moderate & Moderate & Low \\
\hline 5 & D'Apuzzo [18] & Low & Low & Low & Low & Low & Low \\
\hline 6 & Yao DH [19] & Low & Low & Low & Low & Low & Low \\
\hline 7 & Keswani A [8] & Low & Low & Low & Low & Low & Low \\
\hline 8 & $\begin{array}{l}\text { Belmont PJ } \\
{[20]}\end{array}$ & Low & Low & Low & Low & Low & Low \\
\hline 9 & Hart A [7] & Low & Low & Low & Low & Moderate & Low \\
\hline 10 & Bohl DD [6] & Low & Low & High & Low & Low & Low \\
\hline 11 & Culler SD [21] & Low & Moderate & High & High & High & Moderate \\
\hline 12 & Raines BT [22] & Low & Low & Low & Low & Low & Low \\
\hline 13 & $\begin{array}{l}\text { Schairer WW } \\
\text { [23] }\end{array}$ & Low & High & Low & Low & Low & Low \\
\hline 14 & Bosco J [24] & Low & Low & High & High & High & High \\
\hline 15 & $\begin{array}{l}\text { Belmont PJ Jr } \\
{[25]}\end{array}$ & Low & Low & Low & Low & Low & Low \\
\hline 16 & Pugely AJ [26] & Low & Low & Low & Low & Low & Low \\
\hline 17 & $\begin{array}{l}\text { Zmistowski B } \\
\text { [27] }\end{array}$ & Low & Low & Low & Low & Low & Low \\
\hline 18 & Pugely AJ [28] & Low & Low & Low & Low & Low & Low \\
\hline 19 & Cram P [29] & Low & Low & Moderate & Low & Low & Low \\
\hline 20 & Cram P [30] & Low & Moderate & High & Low & Low & Low \\
\hline 21 & Vorhies JS [31] & Low & Low & High & Low & Moderate & Low \\
\hline 22 & Brown NM [32] & Low & Low & High & High & Moderate & Low \\
\hline 23 & Singh JA [33] & Low & Low & Moderate & Moderate & Moderate & Moderate \\
\hline 24 & Husni ME [34] & Low & Moderate & High & High & Low & Low \\
\hline 25 & $\begin{array}{l}\text { Huddleston JI } \\
\text { [35] }\end{array}$ & Low & Low & Moderate & Low & Moderate & Low \\
\hline 26 & Pulido L [36] & Low & Low & Moderate & Moderate & Moderate & Moderate \\
\hline 27 & $\begin{array}{l}\text { Memtsoudis S } \\
{[37]}\end{array}$ & Low & Low & Moderate & Low & Moderate & Moderate \\
\hline 28 & Katz JN [38] & Low & Low & Moderate & Moderate & Moderate & Low \\
\hline
\end{tabular}


weighted mean estimate of effect size, with most primary studies having a large sample size (Fig. 2). A trim and fill test for the random effects model showed that there was no study missing either to the left or to the right of the average, suggesting that missed studies likely would not change our results substantially. Furthermore, Orwin's fail-safe $\mathrm{N}$ indicated that 12 studies with a 30 -dRR of $3 \%$ would be needed to lower the calculated 30-dRR of $4.8 \%$ below 4\%. The RevMan 5.3 software funnel plot for 30dRR of pTKA vs rTKA showed that the distribution of data points was within the confines of the inverse funnel plot but with a tendency for the data points to be to the left of the average line (Fig. 3). This tendency is indicative of literature lacking studies with higher pooled estimate of effect size (odds ratio for readmission rate between primary and revision TKAs).

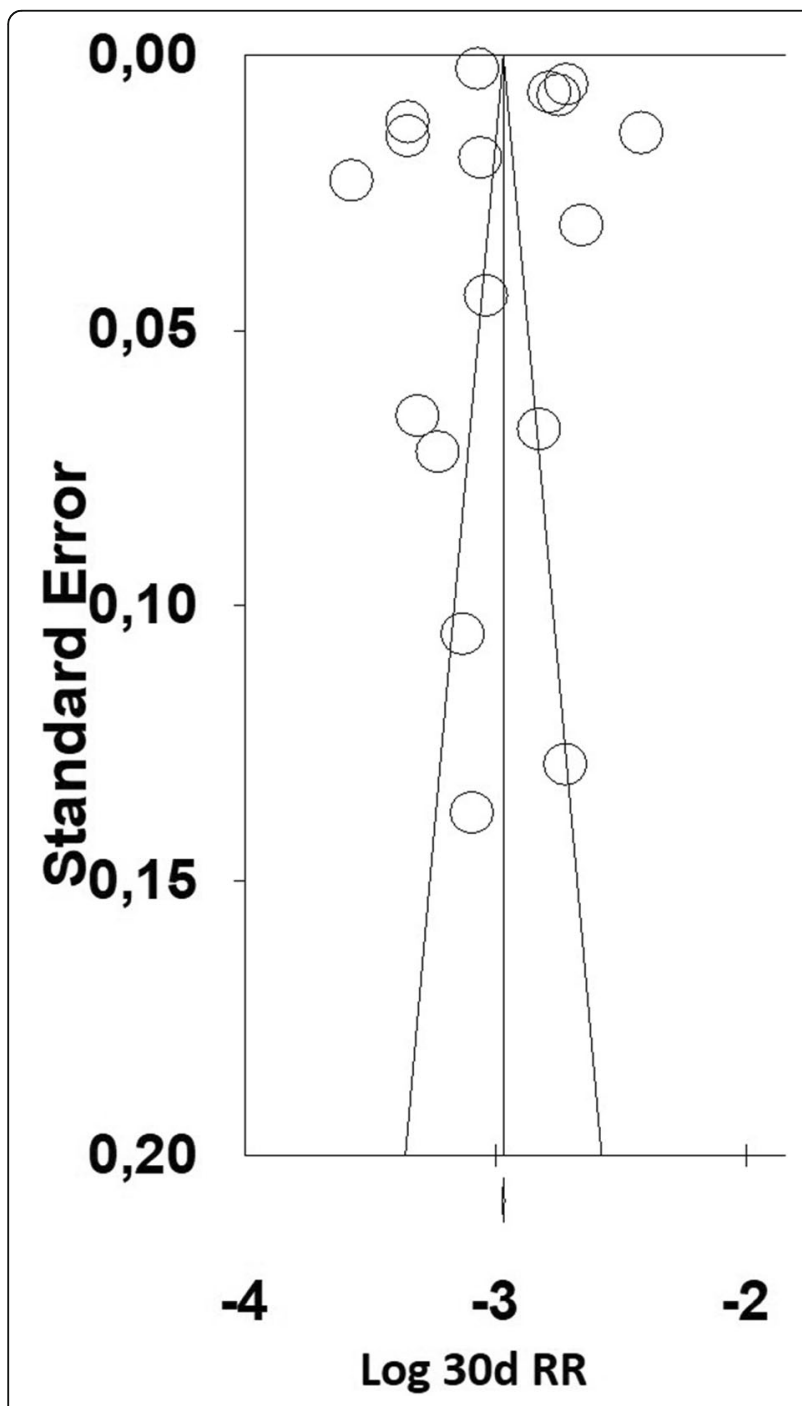

Fig. 2 Funnel plot for the 30-day readmission rate data

\section{Main outcomes of interest}

Thirty-day readmission rate (30-dRR) for pTKA

Relevant data were derived from 17 studies reporting on $5,115,447$ patients $[6,7,14-19,22-24,26-31]$. The pooled estimate of effect size for 30-dRR, was 4.8\% (95\% CI $4.3-5.4 \%$, with significant heterogeneity, $I^{2}=100 \%$ ) (Fig. 4).

\section{Serious adverse event (SAE) rate for PTKA}

Data were obtained from 17 studies reporting on 7,808 , 247 patients $[6,7,15,19,21,22,25,28-30,32-38]$. The pooled estimate of effect size for SAE rate was 5.7\% (95\% CI 4.4-7.2\%, $I^{2}=100 \%$ ). Compared with the 30$\mathrm{dRR}, \mathrm{SAE}$ is significantly higher $\left(p<0.001, \mathrm{X}^{2}\right.$ test).

\section{Main outcomes of interest in revision total knee arthroplasty (rTKA)}

Nine studies, reporting on 670,116 patients, provided relevant data for either 30-dRR or SAE rate in rTKA [6, $8,14,20,23,24,29,36,37]$; 30-dRR was calculated from 6 studies reporting on 330,339 patients $[6,14,20,23,24$, 29]. The respective pooled estimate of effect size for 30d-RR was 7.2\% (95\% CI 6.4-8.0\%, $I^{2}=81 \%$ ). The SAE rate was calculated from 5 studies, reporting on 663,251 patients $[6,8,29,36,37]$. The pooled estimate of effect size for SAE rate was $8.5 \%$ (95\% CI 8.3-8.7\%, $I^{2}=77 \%$ ). Furthermore, direct comparison between pTKA and rTKA, in terms of 30-dRR and SAE rate, was feasible. With respect to $30-\mathrm{dRR}$, relevant data were obtained from 5 studies, reporting on 3,540,261 pTKAs and 328, 585 rTKAs [6, 14, 23, 24, 29]. The odds of readmission within 30 days following pTKA was about half that of rTKA (OR 0.57, 95\% CI 0.53-0.62\%, $p<0.001, I^{2}=45 \%$ ) (Fig. 5). Data on SAE rate were abstracted from 5 studies directly comparing 7,014,965 pTKAs and 658,274 rTKAs. Although the difference between pTKA and rTKA favored pTKA, it failed to reach statistical significance $\left(\mathrm{OR}=0.62,95 \%\right.$ CI $0.38-1.02, p=0.06, I^{2}=$ 100\%) (Fig. 6).

\section{Subgroup analysis Bilateral vs unilateral pTKAs}

Two studies comparing 155,030 bilateral TKAs with 3,679,037 unilateral TKAs provided relevant data only for SAE rate $[7,37]$. The pooled estimate of effect size favored unilateral TKAs (OR $=1.56,95 \%$ CI 1.54 $-1.59, p<0.001, I^{2}=0 \%$, fixed effects model) (Fig. 7). Only a single study compared bilateral vs unilateral TKAs in terms of $30-\mathrm{dRR}$ rate and failed to document any statistically significant difference $(\mathrm{OR}=$ 1.02, 95\% CI 0.8-1.4, $p=0.9$ ) [7]. 


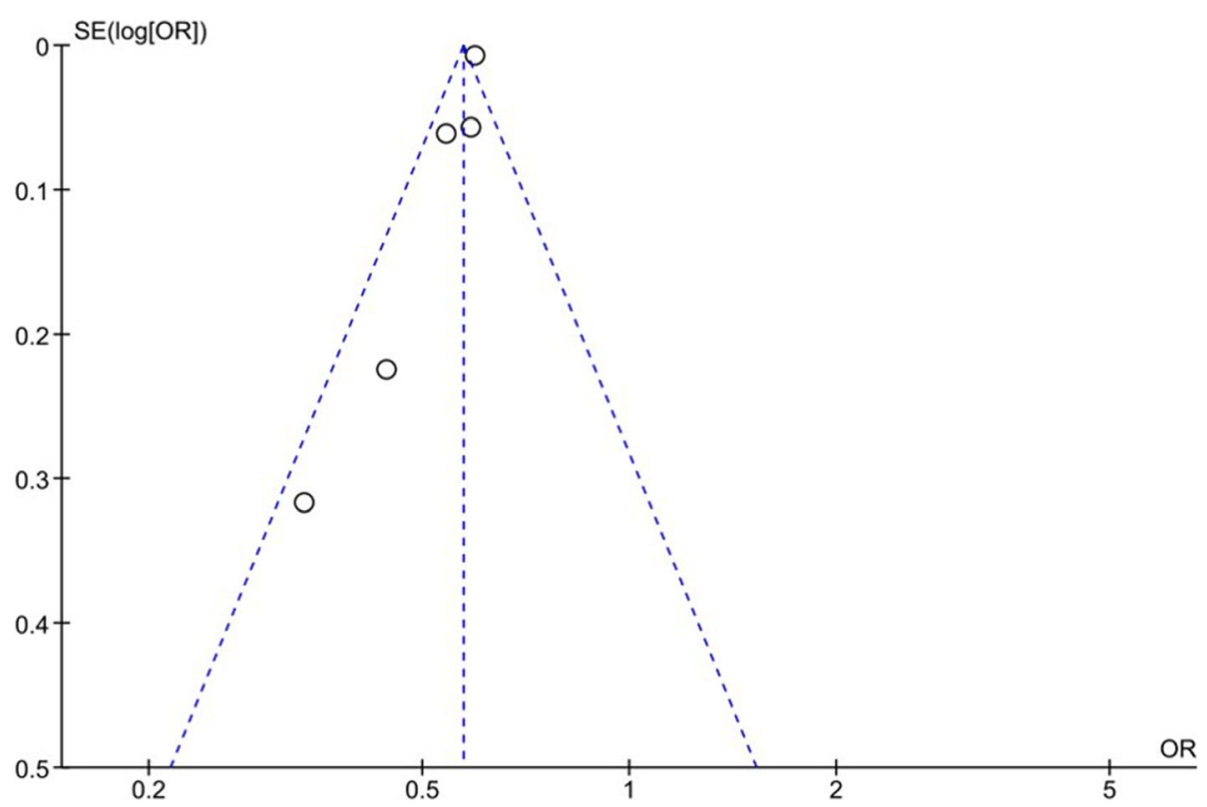

Fig. 3 Funnel plot for 30-day readmission rate data of primary TKA vs revision TKA.

Ross D, 2020

Lehtonen EJ, 2018

Ali AM, 2018

Bottle A, 2018

D'Apuzzo, 2017

Yao DH, 2017

Hart A, 2016

Bohl DD, 2016

Raines BT, 2015

Schairer WW, 2014

Bosco J, 2014

Pugely AJ, J Arthropl 2013

Zmistowski B, 2013

Cram P, JAMA 2012

Cram P, Mayo Clin Proc 2012

Vorhies J, 2012

Brown NM, 2012

Total (random effects)

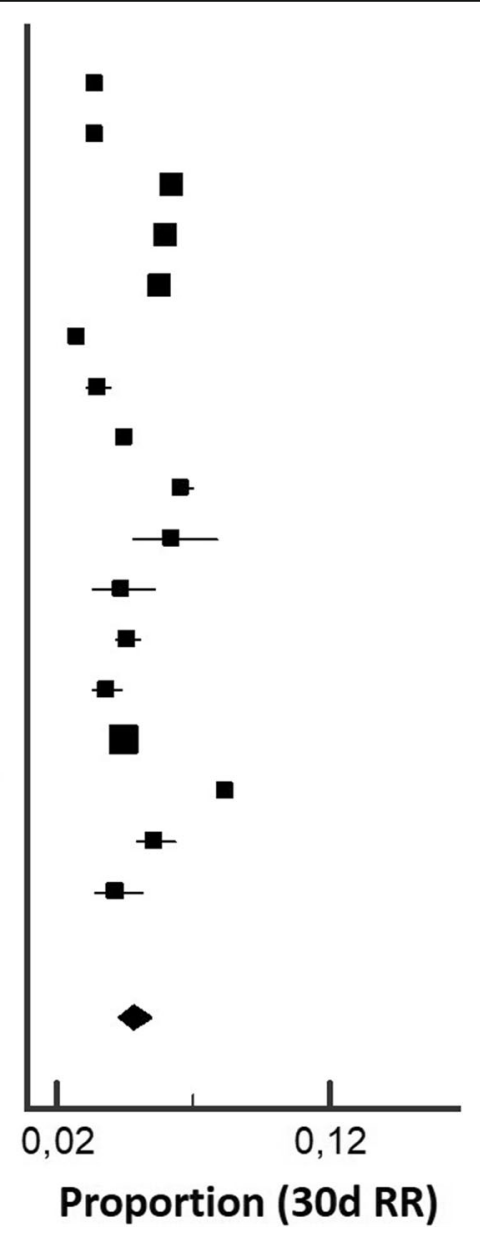

Fig. 4 The pooled estimate of effect size for 30-day readmission rate 


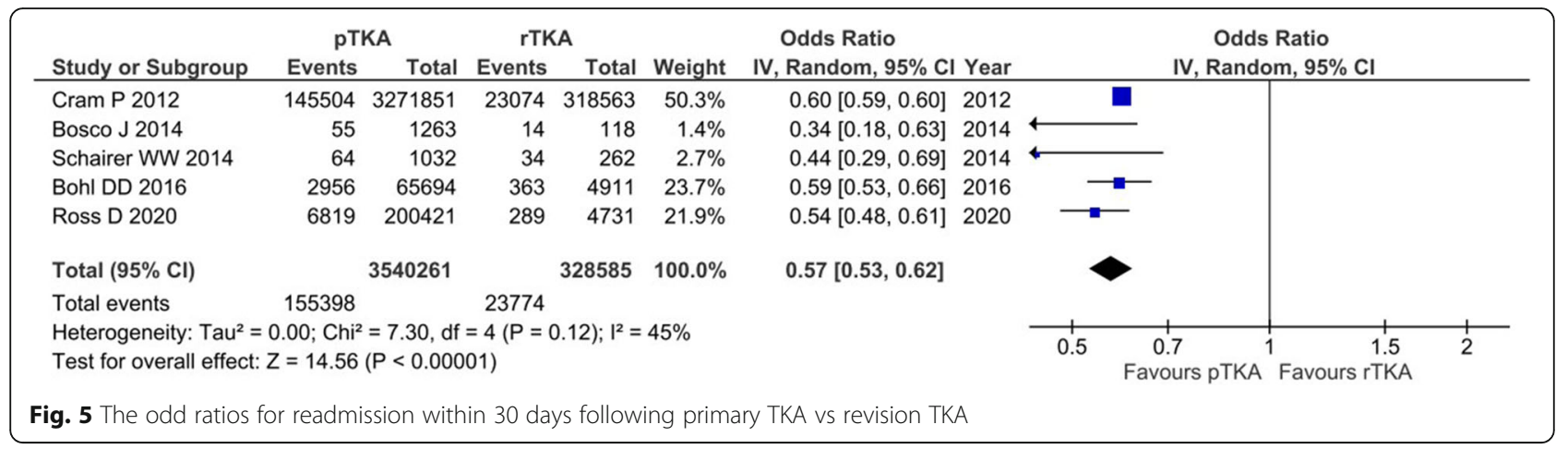

\section{Unicompartmental vs pTKAs}

Relevant data on 30-dRR were extracted from two studies directly comparing 41,255 unicompartmental TKAs with 568,558 pTKAs $[16,32]$. The respective pooled estimate of effect size was in favor of unicompartmental TKA $\left(\mathrm{OR}=0.55,95 \%\right.$ CI $0.52-0.58, p<0.001, I^{2}=0 \%$, fixed effects model). The single study comparing unicompartmental vs pTKA in terms of SAE rate favored the unicompartmental TKA $(\mathrm{OR}=0.36,95 \%$ CI 0.24 $-0.55, p<0.001)[32]$.

\section{Time of patient enrollment}

The primary outcomes of interest were compared based on when surgery occurred (before 2010 versus 2010 to present) and rates of SAE and 30-dRR were compared (Table 3). A statistically significant reduction in both 30$\mathrm{dRR}$ and SAE rate was documented after 2010 ( $\chi^{2}$ test; $p$ $<0.001$ ) (Table 3).

\section{Causes of SAEs and 30-day readmissions}

Causes for both 30-dRR (Table 4) and SAEs (Table 5) following pTKA were explored across primary studies and summarized by pooled analysis. Only relevant causes included in at least 3 primary studies were considered for quantitative synthesis. The most frequent cause of 30-dRRs was VTE (pooled estimate of effect size for VTE: $0.41 \%$; $95 \%$ CI $0.26-0.6 \%$ ), followed by genitourinary (GU) and respiratory complications (Table 4). As for local complications, infections (both deep- periprosthetic and superficial) were the commonest local causes for 30-day readmissions (Table 4). The most frequent causes of adverse events were VTE (pooled estimate of effect size: $1.22 \%$; 95\% CI $0.83-1.70 \%, I^{2}=$ 99.6\%) and GU complications (pooled estimate: 1.22\%; 95\% CI $0.83-1.65 \%, I^{2}=99.5 \%$ ), followed by respiratory and cardiac complications (Table 5). As for local causes of SAEs, the commonest was return to OR, followed by local septic complications (Table 5).

\section{Risk factors for either SAE or 30-dRR}

Twenty risk factors for SAEs or 30d-RR were identified across primary studies based on multivariate analysis. The most frequently documented risk factors with a positive correlation to the outcome of interest in the primary studies were increased age (13 studies) [14-16, 18, 19, 22, 25-29, 36, 37], male gender (10 studies) [7, 8, 14-16, 18, 19, 26, 29, 37], ASA scores 3-4 (8 studies) [8, $15,19,20,22,25,26,28]$, and pulmonary disease $(8$ studies) $[7,8,18,19,22,26,28,35]$. Based on the GRADE analysis, 2 of the most frequently stated risk factors (age, ASA 3-4) had minimal bias, while another two (male gender, pulmonary disease) were obtained from studies of moderate quality. Lastly, 12 risk factors were obtained from studies of low quality (Table 6).

\section{Sensitivity analysis}

To analyze sensitivity, the pooled analysis was repeated after excluding studies with a sample $N$ of over 100,000

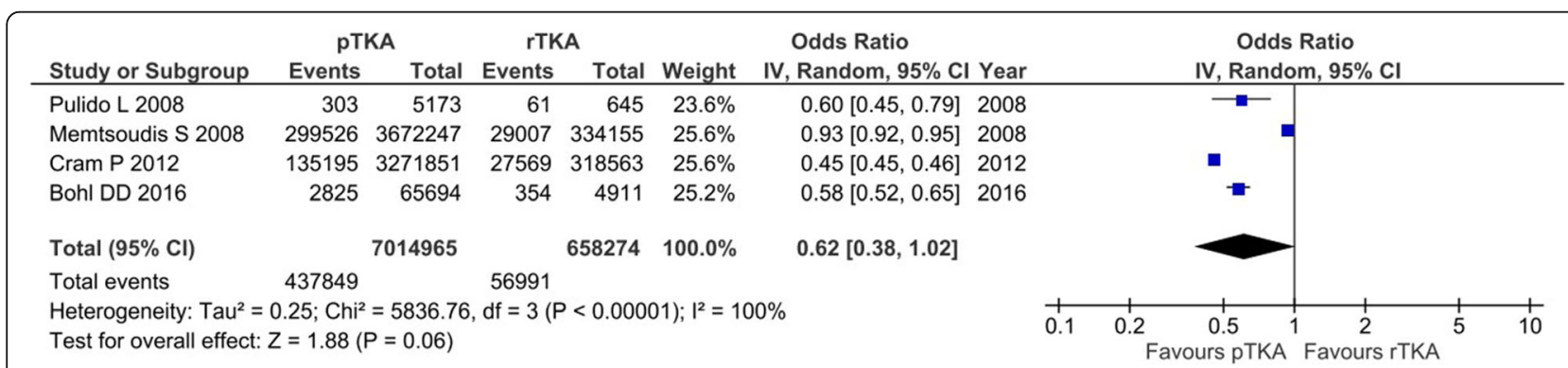

Fig. 6 The odds ratios for serious adverse events following primary TKA vs revision TKA 


\begin{tabular}{|c|c|c|c|c|c|c|c|c|c|c|c|}
\hline \multirow{3}{*}{$\begin{array}{l}\text { Study or Subgroup } \\
\text { Memtsoudis } 2008 \\
\text { Hart A } 2016\end{array}$} & \multirow{2}{*}{$\begin{array}{c}\begin{array}{c}\text { Bilateral } \\
\text { Events }\end{array} \\
18696\end{array}$} & \multirow{2}{*}{$\begin{array}{l}\text { TKAs } \\
\text { Total } \\
153259\end{array}$} & \multirow{2}{*}{$\begin{array}{c}\begin{array}{c}\text { Unilatera } \\
\text { Events }\end{array} \\
299526\end{array}$} & \multirow{2}{*}{$\begin{array}{r}\text { al TKAs } \\
\text { Total } \\
3672247\end{array}$} & \multirow{2}{*}{$\frac{\text { Weight }}{99.7 \%}$} & $\begin{array}{l}\text { Odds Ratio } \\
\text { IV, Fixed, } 95 \% \text { Cl Year }\end{array}$ & \multicolumn{5}{|c|}{$\begin{array}{c}\text { Odds Ratio } \\
\text { IV, Fixed, } 95 \% \mathrm{Cl}\end{array}$} \\
\hline & & & & & & $1.56[1.54,1.59] 2008$ & & & & & \\
\hline & 67 & 1771 & 151 & 6790 & $0.3 \%$ & $1.73[1.29,2.32] 2016$ & & & & & $\rightarrow$ \\
\hline Total $(95 \% \mathrm{Cl})$ & & 155030 & & 3679037 & $100.0 \%$ & $1.56[1.54,1.59]$ & & & & $\downarrow$ & \\
\hline Total events & 18763 & & 299677 & & & & & & & & \\
\hline $\begin{array}{l}\text { Heterogeneity: } \text { Chi }^{2}= \\
\text { Test for overall effect: }\end{array}$ & $\begin{array}{l}.45, d f=1 \\
=55.82(\end{array}$ & $\begin{array}{l}(P=0.5 \\
P<0.00 c\end{array}$ & $\begin{array}{l}0) ; I^{2}=0 \% \\
001)\end{array}$ & & & & 0.5 & $\begin{array}{cc}0.7 & 1 \\
\text { Favours Bilateral TKAs }\end{array}$ & $\begin{array}{l}\text { Favours } \\
\end{array}$ & $\begin{array}{c}1.5 \\
\text { Unilateral TKAs }\end{array}$ & 2 \\
\hline
\end{tabular}

participants (Table 7). New results did not differ substantially from the original results. The pooling analysis was repeated after excluding studies with at least 2 domains of "high risk" in the QUIPS instrument, and this also did not produce materially different results compared to the original. These findings suggest that our results are robust.

\section{Discussion}

Our results show that elective TKA is associated with a significant rate of serious adverse events and hospital readmissions after surgery. The SAE rate for pTKA is $5.7 \%$ (95\% CI $4.4-7.2 \%$ ), while the $30 \mathrm{~d}-\mathrm{RR}$ rate is $4.8 \%$ (95\% CI $4.3-5.4 \%)$. For rTKA, the SAE rate is $8.5 \%(95 \%$ CI $8.3-8.7 \%$ ), while the 30d-RR rate is $7.2 \%$ (95\% CI 6.4 $-8.0 \%)$. The $30-d R R$ is significantly lower than the SAE rate for primary and revision TKAs. Primary TKA is associated with fewer hospital readmissions than is revision TKA (Fig. 5), consistent with literature showing that patients with revision TKA, whether for infection or for other causes, are more likely to have an unplanned readmission to the hospital than are patients with primary TKA [23]. The odds of hospital readmission for rTKA were twice as high as those for pTKA, while the odds of SAEs in bilateral TKAs were 1.5 times greater than in unilateral TKAs. Contrasting studies done prior to 2010 with later studies demonstrates a significant reduction in both SAE rate and 30-dRR since 2010 ( $\chi^{2}$ test; $p<0.001$ ) (Table 3).

Hospital readmission after surgery is associated with poor patient outcomes and increased medical costs [39]. Although hospital readmission rates are not highly correlated with mortality rates, short-term readmissions have been identified as an important cause of escalating health care costs [40]. The 30-dRR is related to the SAE rate in that both measures characterize unanticipated harms to the patient, unplanned expenses to the medical system, and/or unperceived problems in either the patient or the medical system. Yet the 30-dRR should not be construed as a measure of failure, because hospital readmission can represent a successful rescue of the patient from dire consequences of surgery [2]. Rehospitalization may thus reflect good medical judgement rather than bad medical care [2].

The leading causes of SAEs and 30-dRR were surgical complications requiring operative treatment, VTE, and deep infection (Tables 4 and 5). Return to OR constitutes a generalized and composite cause of SAEs and 30$\mathrm{dRR}$, which cannot be split further to its constituent elements due to lack of available data. With the implementation of strict protocols regarding VTE prevention [41], symptomatic VTE following TKA has reportedly been reduced to $0.3 \%$ [42]. Even so, VTE remains among the primary causes of 30-dRR and SAE following TKA. Deep infection is also a problem, despite new protocols that have been developed for TKA, including use of antibiotics [43, 44], preoperative nasal screening for drug-resistant bacteria and subsequent decolonization procedures $[45,46]$, and strategies to optimize air quality in operating rooms $[47,48]$.

Readmission following orthopedic surgery was linked to surgical site infection in $25.4 \%$ of cases in one study [49]. Reasons for hospital readmission in a sample of 4057 Medicare patients who had TKA were largely medical, rather than surgical [31]. The reported overall 30dRR was $5.6 \%$, and the 10 most common reasons for readmission were congestive heart failure (20.4\%), chronic ischemic heart disease (13.9\%), cardiac dysrhythmias (12.5\%), pneumonia (10.8\%), osteoarthrosis (9.4\%), general symptoms $(7.4 \%)$, acute myocardial infarction

Table 3 Primary outcomes of interest based on time of patients' enrollment

\begin{tabular}{|c|c|c|c|c|c|c|}
\hline & Number of studies (Refs) & Sample size & Pooled estimate of effect size (\%) & $95 \% \mathrm{Cl}$ & Heterogeneity (\%) & $\begin{array}{l}\mathrm{X}^{2} \\
\text { test }\end{array}$ \\
\hline AE rate, before 2010 & 12 & $7,173,611$ & 6.5 & $4.6-8.2$ & 100 & $p<0.001$ \\
\hline AE rate, from 2010 on & 6 & 639,613 & 4.7 & $1.7-9.0$ & 100 & \\
\hline 30-dRR, before 2010 & 6 & $3,364,870$ & 5.4 & $3.8-7.3$ & 100 & $p<0.001$ \\
\hline 30-dRR, from 2010 on & 7 & 605,587 & 4.3 & $3.2-5.6$ & 100 & \\
\hline
\end{tabular}


Table 4 Pooled causes of 30-day readmissions for pTKA

\begin{tabular}{|c|c|c|c|c|c|c|}
\hline & $\begin{array}{l}\text { Number of reporting studies } \\
\text { [refs] }\end{array}$ & $\begin{array}{l}\text { Sample } \\
\text { size }\end{array}$ & $\begin{array}{l}N \text { of events ( } 30 \mathrm{~d} \\
\text { readmissions) }\end{array}$ & $\begin{array}{l}\text { Rate } \\
\text { (\%) }\end{array}$ & $95 \% \mathrm{Cl}$ & $\begin{array}{l}I^{2} \\
(\%)\end{array}$ \\
\hline \multicolumn{7}{|l|}{ Systemic conditions } \\
\hline VTE & $4[15,19,26,27]$ & 225,523 & 881 & 0.41 & $0.26-0.60$ & 96.4 \\
\hline GU complications & $3[15,19,26]$ & 220,316 & 341 & 0.18 & $0.06-0.34$ & 98.0 \\
\hline Respiratory complications & $3[15,19,26]$ & 220,316 & 373 & 0.17 & $0.09-0.26$ & 94.5 \\
\hline Cardiac complications & $4[15,19,26,27]$ & 225,523 & 239 & 0.15 & $0.08-0.24$ & 93.2 \\
\hline Sepsis & $3[15,19,26]$ & 220,316 & 313 & 0.15 & $0.05-0.3$ & 98.0 \\
\hline Stroke / CVA & $3[15,19,26]$ & 220,316 & 45 & 0.02 & $\begin{array}{l}0.004 \\
-0.05\end{array}$ & 90.0 \\
\hline \multicolumn{7}{|l|}{ Local conditions } \\
\hline Superficial infection & $3[15,19,26]$ & 220,316 & 644 & 0.32 & $0.10-0.65$ & 99.0 \\
\hline $\begin{array}{l}\text { Deep + periprosthetic } \\
\text { infection }\end{array}$ & $3[15,26,27]$ & 154,230 & 455 & 0.56 & $0.16-1.21$ & 98.3 \\
\hline
\end{tabular}

VTE, venous thromboembolism; GU, genitourinary complications (renal insufficiency, renal failure, urinary tract infections [UTI]; CVA, cerebrovascular accident.

Respiratory complications: pneumonia, unplanned intubation, ventilation $>48 \mathrm{~h}$. Cardiac complications: myocardial infarction, cardiac arrest

(7.0\%), care involving other rehabilitation procedures (6.3\%), diabetes mellitus (6.3\%), and disorders of fluid, electrolyte, and acid-base balance (5.9\%). Thus, the top 10 causes of readmission listed did not include VTE [31], which were what we found to be important (Table 2).
We have documented a clear decline of both 30-dRR and SAEs over the study period (Table 3). Many factors have potentially contributed to this result, such as implementation of stricter protocols for VTE prevention, patient decolonization procedures, air quality optimizing strategies in operating theaters, preoperative cardiac

Table 5 Pooled causes of SAEs for pTKAs

Number of reporting studies [refs] $\quad$ Sample size $\quad N$ of events (SAEs) $\quad$ Rate (\%) $\quad 95 \% \mathrm{Cl} \quad I^{2}$

\begin{tabular}{|c|c|c|c|c|c|c|}
\hline \multicolumn{7}{|l|}{ Systemic complications } \\
\hline VTE & $\begin{array}{l}11 \\
{[7,15,19,21,25,28,30,33,35,36,38]}\end{array}$ & 770,255 & 7797 & 1.22 & $0.83-1.70$ & 99.6 \\
\hline GU complications & $7[15,19,25,28,35-37]$ & $3,917,328$ & 37,180 & 1.22 & $0.83-1.67$ & 99.5 \\
\hline Respiratory complications & $10[7,15,19,21,25,28,35-38]$ & $4,358,372$ & 44,485 & 0.45 & $0.23-0.76$ & 99.8 \\
\hline Cardiac complications & $12[7,15,19,21,25,28,30,33,35-38]$ & $4,442,502$ & 42,278 & 0.31 & $0.12-0.6$ & 99.8 \\
\hline Sepsis & $\begin{array}{l}7 \\
{[6,15,19,25,28,30,36]}\end{array}$ & 373,454 & 887 & 0.26 & $0.17-0.38$ & 97.2 \\
\hline Stroke/CVA & $\begin{array}{l}6 \\
{[7,19,25,28,36,37]}\end{array}$ & $3,784,876$ & 5433 & 0.10 & $0.04-0.19$ & 97.2 \\
\hline Mortality & $12[6,7,19,21,25,28,30,33,35-38]$ & $4,370,987$ & 11,424 & 0.16 & $0.09-0.24$ & 99.0 \\
\hline \multicolumn{7}{|l|}{ Local complications } \\
\hline Return to OR & $\begin{array}{l}3 \\
{[7,19,28]}\end{array}$ & 92,135 & 779 & 1.04 & $0.57-1.65$ & 97.4 \\
\hline Superficial infection & $\begin{array}{l}5 \\
{[15,19,25,28,36]}\end{array}$ & 243,048 & 1066 & 0.43 & $0.21-0.72$ & 98.6 \\
\hline Deep + periprosthetic infection & $12[6,7,15,19,21,25,28,30,33,36-38]$ & $4,506,163$ & 10,591 & 0.30 & $0.24-0.37$ & 98.3 \\
\hline Wound dehiscence & $\begin{array}{l}5 \\
{[19,25,28,35,37]}\end{array}$ & $3,774,946$ & 1458 & 0.13 & $0.05-0.26$ & 98.0 \\
\hline Implant-related compl. & $\begin{array}{l}4 \\
{[19,28,35,36]}\end{array}$ & 92,551 & 32 & 0.04 & $0.01-0.08$ & 72.0 \\
\hline Periprosthetic fractures & $\begin{array}{l}3 \\
{[19,35,36]}\end{array}$ & 78,499 & 23 & 0.10 & $0.008-0.3$ & 91.0 \\
\hline
\end{tabular}

VTE, venous thromboembolism; GU, genitourinary complications (renal insufficiency, renal failure, urinary tract infections [UTI]; CVA, cerebrovascular accident; OR, operating theatre. Respiratory complications: pneumonia, unplanned intubation, ventilation $>48 \mathrm{~h}$. Cardiac complications: myocardial infarction, cardiac arrest. 
Table 6 Risk factors for readmission or AEs with GRADE analysis

\begin{tabular}{|c|c|c|c|c|c|c|c|c|c|c|c|}
\hline \multirow[b]{2}{*}{ Risk factor } & \multirow[b]{2}{*}{$\begin{array}{l}\text { Studies with } \\
\text { statistically } \\
\text { positive } \\
\text { correlation } \\
\text { (refs) }\end{array}$} & \multirow[b]{2}{*}{$\begin{array}{l}\text { Studies } \\
\text { with no } \\
\text { correlation } \\
\text { (refs) }\end{array}$} & \multirow[b]{2}{*}{$\begin{array}{l}\text { Studies } \\
\text { not } \\
\text { reporting }\end{array}$} & \multicolumn{8}{|c|}{ GRADE analysis } \\
\hline & & & & $\begin{array}{l}\text { Study } \\
\text { limitations }\end{array}$ & Inconsistency & $\begin{array}{l}\text { Indirect- } \\
\text { ness }\end{array}$ & $\begin{array}{l}\text { Impreci- } \\
\text { sion }\end{array}$ & $\begin{array}{l}\text { Publica- } \\
\text { tion } \\
\text { bias }\end{array}$ & $\begin{array}{l}\text { Mod/ } \\
\text { Large } \\
\text { effect } \\
\text { size }\end{array}$ & $\begin{array}{l}\text { Dose } \\
\text { effect }\end{array}$ & $\begin{array}{l}\text { Overall } \\
\text { quality }\end{array}$ \\
\hline Age & 13 & 2 & 3 & v & $\mathrm{v}$ & $v$ & $v$ & $v$ & $x$ & $\vee$ & $(+++)$ \\
\hline Obesity & 6 & 4 & 7 & $v$ & $x$ & $x$ & $x$ & $v$ & $x$ & $x$ & $(+)$ \\
\hline $\mathrm{DM}$ & 5 & 3 & 11 & v & $x$ & $x$ & $x$ & $?$ & $x$ & $x$ & $(+)$ \\
\hline $\begin{array}{l}\text { Cardiac } \\
\text { disease }\end{array}$ & 5 & 2 & 11 & v & v & $x$ & $x$ & $x$ & $x$ & $x$ & $(+)$ \\
\hline Hypertension & 2 & 4 & 12 & v & $x$ & $x$ & $x$ & $x$ & $x$ & $x$ & $(+)$ \\
\hline Previous CVA & 1 & 2 & 16 & $v$ & $x$ & $x$ & $x$ & $x$ & $x$ & $x$ & $(+)$ \\
\hline ASA: $3-4$ & 8 & 1 & 9 & v & v & v & v & $?$ & $x$ & $v$ & $(+++)$ \\
\hline $\begin{array}{l}\text { Operative time } \\
>135 \mathrm{~min}\end{array}$ & 3 & 2 & 14 & $v$ & $x$ & $x$ & $x$ & $x$ & $x$ & $v$ & $(+)$ \\
\hline $\operatorname{LOS}>4 \mathrm{~d}$ & 5 & 0 & 14 & $v$ & $v$ & $x$ & $v$ & $x$ & $x$ & $x$ & $(++)$ \\
\hline Female gender & 4 & 2 & 2 & $x$ & $x$ & v & v & $v$ & $x$ & $x$ & $(++)$ \\
\hline Male gender & 10 & 2 & 1 & $v$ & $x$ & $v$ & $v$ & $v$ & $x$ & $x$ & $(++)$ \\
\hline $\begin{array}{l}\text { Anesthesia } \\
\text { (general vs } \\
\text { spinal, } \\
\text { epidural, } \\
\text { regional) }\end{array}$ & 2 & 0 & 17 & v & $?$ & $x$ & v & $x$ & $x$ & $x$ & $(+)$ \\
\hline Black race & 5 & 3 & 11 & $v$ & $?$ & $x$ & v & $x$ & $x$ & $x$ & $(+)$ \\
\hline $\begin{array}{l}\text { In-hospital } \\
\text { complications }\end{array}$ & 3 & 0 & 15 & v & v & $x$ & v & $x$ & $v$ & $x$ & $(++)$ \\
\hline $\begin{array}{l}\text { Discharge } \\
\text { disposition } \\
\text { (any facility vs } \\
\text { home) }\end{array}$ & 5 & 1 & 13 & v & v & $x$ & v & $x$ & $x$ & $x$ & $(++)$ \\
\hline $\begin{array}{l}\text { Pulmonary } \\
\text { disease }\end{array}$ & 8 & 1 & 9 & v & $v$ & v & v & $?$ & $x$ & $x$ & $(++)$ \\
\hline $\begin{array}{l}\text { Fluid } \\
\text { electrolyte } \\
\text { disorder }\end{array}$ & 2 & 2 & 15 & $x$ & $x$ & $x$ & $x$ & $x$ & $x$ & $x$ & $(+)$ \\
\hline Renal failure & 4 & 1 & 14 & v & $?$ & $x$ & v & $x$ & $x$ & $x$ & $(+)$ \\
\hline $\begin{array}{l}\text { Simultaneous } \\
\text { bilateral TKAs }\end{array}$ & 2 & 3 & 14 & $x$ & $x$ & $x$ & $x$ & $x$ & $x$ & $x$ & $(+)$ \\
\hline Revision TKA & 4 & 0 & 14 & $x$ & v & $x$ & v & $x$ & $x$ & $x$ & $(+)$ \\
\hline
\end{tabular}

GRADE factors: $\checkmark$, no serious limitations; $\boldsymbol{x}$, serious limitations (or not present for moderate/large effect size, dose effect); ?, unclear whether limitations are serious; overall quality of evidence: + , low; ++ , moderate; +++ , high.

The risk factors that had $\geq 5$ scores of "no serious limitations" were determined to be high quality. Those that had 3-4 scores of "no serious limitations" were determined to be of moderate quality. Risk factors with $<3$ scores of "no serious limitations" were determined to be low quality.

clearance, tighter diabetic control, and weight loss programs.

\section{Limitations and strengths}

The results of our primary analysis are characterized by a high degree of statistical heterogeneity, which indicates that patient populations in the pooled studies were not identical. Several included studies were type 2 prognostic factor studies [50] based on large registries. Registries are retrospective, so the populations within them are expected to differ in terms of factors such as baseline and demographic characteristics, comorbidities, interventional protocols, follow-up strategies, and so on. Due to this diversity, outcomes differed among the constituent studies to a greater degree than expected by chance.

Meta-analyses based on retrospective observational studies are prone to bias because they bring together material from many sources, with potential differences in demographic characteristics of included cohorts, inconsistent definitions of outcomes of interest, different 
Table 7 Results of sensitivity analysis

\begin{tabular}{|c|c|c|c|c|c|c|}
\hline Outcome of interest & $n$ reporting studies & $n$ events & OR or rate (\%) & $95 \% \mathrm{Cl}$ & Statistical model & $P^{2}$ \\
\hline 30-dRR & 11 & 250,905 & 4.8 & $3.5-6.3$ & RE & $99.5 \%$ \\
\hline AEs rate & 13 & 373,290 & 5.4 & $3.7-7.4$ & RE & $99.8 \%$ \\
\hline \multicolumn{7}{|l|}{ Subgroup analysis } \\
\hline PTKA vs rTKA: OR, AEs & 2 & $\begin{array}{l}\text { pTKA: } 70,867 \\
\text { rTKA: } 5556\end{array}$ & OR: 0.6 & $0.5-0.7$ & FE & $0 \%$ \\
\hline pTKA vs rTKA: OR, 30-dRR & 4 & $\begin{array}{l}\text { pTKA: } 268,410 \\
\text { rTKA: } 10,022\end{array}$ & OR: 0.6 & $0.5-0.6$ & RE & $37 \%$ \\
\hline 30-dRR (rTKA) & 5 & 11,776 & 7.6 & $6.2-9.0$ & RE & $83 \%$ \\
\hline AEs (rTKA) & 3 & 10,533 & 8.0 & $7.0-9.0$ & RE & $60 \%$ \\
\hline
\end{tabular}

pTKA, primary TKA; $r T K A$, revision TKA; $R E$, random effects model; $F E$, fixed effects model

surgical and follow-up protocols, and so on. We tried to minimize heterogeneity as an issue by having a focused review question, using strict eligibility criteria, and having clear definitions of outcomes of interest. Because there was significant statistical heterogeneity, we used a random effects model, but the combined estimates of effect size should be interpreted with caution. It is more prudent to consider the $95 \%$ confidence intervals rather than the point estimate of each outcome of interest. Only when the pooled estimate of an effect size is derived from high-quality randomized clinical trials, using similar treatment protocols, can an effect size estimate be defined with accuracy. However, in the present report, we synthesize results from a huge group of patients in a statistically valid way, using all existing material from large multicenter series and registries. We believe our conclusions are useful in describing current trends related to short-term outcomes of TKA.

It is possible that $30-\mathrm{dRR}$ may be a more consistent metric than the SAE rate. Comparisons of SAE may be particularly sensitive to the type of database used (administrative claims versus clinical registry), the time period of the comparison, the definitions of variables of interest, and the specific population captured [51]. We therefore explored potential sources of heterogeneity by subgroup analysis. Heterogeneity was markedly reduced in some subgroup comparisons; for example, heterogeneity was $45 \%$ in comparing 30 -dRR of pTKA to rTKA, but heterogeneity was $0 \%$ when pTKA was compared with unicompartmental TKA. Because data pooling within subgroups could be done without significant heterogeneity, this implies that the high initial level of heterogeneity may be a function of several diverse subgroups within the included material. Heterogeneity is often statistically significant in our results because sample sizes are large enough that even small differences become significant.

Several additional limitations of this research are noteworthy: 30-dRR may underestimate actual negative outcomes because procedure-related hospital readmissions-especially for periprosthetic joint infectioncould occur with a delay longer than 30 days [52]; facilities with a poor record of 30-day readmission may be reluctant to report this fact in the literature, so the published 30-dRR may underestimate the actual 30-dRR; and some potentially important SAEs, such as opioid addiction, are not generally reported and therefore could not be collated here.

A strength of our study is that the risk of bias in component studies was assessed with the QUIPS tool. Our exploration of publication bias indicates that it was unlikely that we failed to consider reports that could alter our results. Consistent with this, the confidence intervals of our findings are narrow, and the sensitivity analysis suggests that our results are robust.

Another strength of our study is that it may help patients to evaluate the risks, benefits, and timing of TKA more objectively. TKA is generally accepted as the definitive treatment for advanced knee OA after patients fail non-operative treatments [53]. This reasoning suggests that there is no point in postponing the inevitable; if TKA benefits most patients, why not offer that benefit as soon as possible? However, there are several important objections to the strategy of early replacement. First, TKA may not be a definitive treatment for all patients; if patients suffer treatmentrelated SAEs, as documented here, then additional treatment will be required. Second, hardware failure with time can lead to a need for revision surgery, and revision surgery is more prone to complications than is pTKA (Fig. 2). Postponing surgery until no revision is likely to be needed limits costs and makes sense for the patient, provided that effective symptomatic relief can be offered prior to TKA [54]. Third, patients may opt for premature TKA because of unrealistic expectations of positive outcomes, undervaluation of the risk of negative outcomes, and lack of knowledge about competing treatments [55]. 


\section{Conclusions}

Our results suggest that despite advances in the surgical technique and implant design, TKA procedures are still characterized by a non-negligible complication rate, which is more pronounced in revision surgery. Leading causes of SAEs and readmissions were surgical complications, VTE events, and deep infections. However, there has been an improvement in SAE and readmission rates over the past decade, suggesting that further improvements in outcome may be expected in years to come.

\section{Abbreviations}

TKA: Total knee arthroplasty; SAE: Serious adverse event; 30-dRR: Thirty-day readmission rate; pTKA: Primary TKA; rTKA: Revision TKA; OR: Operating room; NSQIP: National Surgical Quality Improvement Program; VA: Veteran Affairs; CMS: Center for Medicare and Medicaid Services; PRISMA: Preferred Reporting Items for Systematic Reviews and Meta-Analyses; QUIPS: Quality in Prognosis Studies; GRADE: Grading of Recommendations Assessment, Development and Evaluation; VTE: Venous thromboembolism; MI: Myocardial infarction; HF: Heart failure; MESH: Medical Subject Headings
\end{abstract}

\section{Supplementary Information}

The online version contains supplementary material available at https://doi. org/10.1186/s13018-021-02358-w.

Additional file 1. PRISMA 2009 Checklist.

\section{Acknowledgements}

All who contributed to this work are acknowledged with authorship.

\section{Authors' contributions}

All authors made substantial contributions to the conception of the work and to the analysis and interpretation of data; and drafted or substantively revised the work. All authors approved the submitted version. All authors agreed to be personally accountable for their contribution and to ensure that questions related to the accuracy or integrity of any part of the work are appropriately investigated and resolved. The authors read and approved the final manuscript.

\section{Funding}

No funding of any kind was received for this work.

\section{Availability of data and materials}

The datasets analyzed in the current study are available from the corresponding author on reasonable request.

\section{Declarations}

Ethics approval and consent to participate

Not applicable

\section{Consent for publication}

Not applicable

\section{Competing interests}

The authors declare that they have no competing interests.

\section{Author details}

${ }^{1}$ Orthopaedic Department, Limassol General Hospital, Limassol, Cyprus. ${ }^{2}$ Academic Department of Trauma \& Orthopaedics, School of Medicine, University of Leeds, Leeds, UK. ${ }^{3}$ NIHR Leeds Biomedical Research Unit, Chapel Allerton Hospital, Leeds, UK. ${ }^{4}$ Department Of Orthopedic Surgery, University of Arizona College of Medicine, Phoenix, AZ, USA. ${ }^{5}$ Department of Orthopedic Surgery, Louisiana State University Medical Center, New Orleans, LA, USA. ${ }^{6}$ Present address: 103 Van Doren Place, Chapel Hill, NC 27517, USA.
Received: 12 January 2021 Accepted: 17 March 2021

Published online: 31 March 2021

\section{References}

1. Jencks SF, Williams MV, Coleman EA. Rehospitalizations among patients in the Medicare fee-for-service program. N Engl J Med. 2009;360(14):1418-28. https://doi.org/10.1056/NEJMsa0803563.

2. Brown EG, Burgess D, Li CS, Canter RJ, Bold RJ. Hospital readmissions: necessary evil or preventable target for quality improvement? Ann Surg. 2014;260(4):583-9. https://doi.org/10.1097/SLA.0000000000000923.

3. Bernatz JT, Tueting $J$, Anderson PA. Thirty-day readmission rates in orthopedics: a systematic review and meta-analysis. PLoS One. 2015;10(4): e0123593. https://doi.org/10.1371/journal.pone.0123593.

4. Fife CE, Walker D, Thomson B. Electronic health records, registries, and quality measures: What? Why? How? Adv Wound Care (New Rochelle). 2013;2(10):598-604. https://doi.org/10.1089/wound.2013.0476.

5. Lavernia CJ, Villa JM, lacobelli DA. Readmission rates in the state of Florida: a reflection of quality? Clin Orthop Relat Res. 2013;471(12):3856-62. https:// doi.org/10.1007/s11999-013-2849-2.

6. Bohl DD, Samuel AM, Basques BA, Della Valle CJ, Levine BR, Grauer JN. How much do adverse event rates differ between primary and revision total joint arthroplasty? J Arthroplasty. 2016;31(3):596-602.

7. Hart A, Antoniou J, Brin YS, Huk OL, Zukor DJ, Bergeron SG. Simultaneous bilateral versus unilateral total knee arthroplasty: a comparison of 30-day readmission rates and major complications. J. Arthroplast. 2016;31(1):31-5. https://doi.org/10.1016/j.arth.2015.07.031.

8. Keswani A, Lovy AJ, Robinson J, Levy R, Chen D, Moucha CS. Risk factors predict increased length of stay and readmission rates in revision joint arthroplasty. J. Arthroplast. 2016;31(3):603-8. https://doi.org/10.1016/j.arth.2 015.09.050.

9. Liberati A, Altman DG, Tetzlaff J, Mulrow C, Gøtzsche PC, loannidis JP, et al. The PRISMA statement for reporting systematic reviews and meta-analyses of studies that evaluate healthcare interventions: explanation and elaboration. BMJ. 2009;339(jul21 1):b2700. https://doi.org/10.1136/bmj.b2700.

10. Hayden JA, van der Windt DA, Cartwright JL, Côté P, Bombardier C. Assessing bias in studies of prognostic factors. Ann Intern Med. 2013;158(4): 280-6.

11. Hueget A, Hayden JA, Stinson J, McGrath PJ, Chambers CT, Tougas ME, et al Judging the quality of evidence in reviews of prognostic factor research: adapting the GRADE framework. Syst Rev. 2013;2(1):71. https://doi.org/10.11 86/2046-4053-2-71.

12. Cochran $W$. The combination of estimates from different experiments. Biometrics. 1954;10(1):101-29. https://doi.org/10.2307/3001666.

13. Higgins JP, Thompson SG, Deeks JJ, Altman DG. Measuring inconsistency in meta-analyses. BMJ. 2003;327(7414):557-60. https://doi.org/10.1136/bmj.327. 7414.557

14. Ross TD, Dvorani E, Saskin R, Khoshbin A, Atrey A, Ward SE. Temporal trends and predictors of thirty-day readmissions and emergency department visits following total knee arthroplasty in Ontario between 2003 and 2016. J Arthroplasty. 2020;35(2):364-70. https://doi.org/10.1016/j.arth.2019.09.015.

15. Lehtonen EJ, Hess MC, McGwin G Jr, Shah A, Godoy-Santos AL, Naranje S. Risk factors for early hospital readmission following total knee arthroplasty. Acta Orthop Bras. 2018;26(5):309-13. https://doi.org/10.1590/1413-7852201 82605190790 .

16. Ali AM, Loeffler MD, Aylin P, Bottle A. Predictors of 30-day readmission after total knee arthroplasty: analysis of 566,323 procedures in the United Kingdom. J Arthroplasty. 2019;34(2):242-8.

17. Bottle A, Loeffler MD, Aylin P, Ali AM. Comparison of 3 types of readmission rates for measuring hospital and surgeon performance after primary total hip and knee arthroplasty. J Arthroplasty. 2018;33(7):2014-9.

18. D'Apuzzo M, Westrich G, Hidaka C, Pan TJ, Lyman S. All-cause versus complication-specific readmission following total knee arthroplasty. J Bone Joint Surg Am. 2017;99(13):1093-103. https://doi.org/10.2106/JBJS.16.00874.

19. Yao DH, Keswani A, Shah CK, Sher A, Koenig KM, Moucha CS. Home discharge after primary elective total joint arthroplasty: post discharge complication, timing and risk factor analysis. J Arthroplasty. 2017;32(2):37580. https://doi.org/10.1016/j.arth.2016.08.004

20. Belmont PJ Jr, Goodman GP, Rodriguez M, Bader JO, Waterman BR, Schoenfeld AJ. Predictors of hospital readmission following revision total knee arthroplasty. Knee Surg Sports Traumatol Arthrosc. 2016;24(10):3329_ 38. https://doi.org/10.1007/s00167-015-3782-6. 
21. Culler SD, Jevsevar DS, Shea KG, McGuire KJ, Wright KK, Simon AW. The incremental hospital cost and length-of-stay associated with treating adverse events among Medicare beneficiaries undergoing TKA. J Arthroplasty. 2016;31(1):42-8. https://doi.org/10.1016/j.arth.2015.07.037.

22. Raines BT, Ponce BA, Reed RD, Richman JS, Hawn MT. Hospital acquired conditions are the strongest predictor for early readmission: an analysis of 26,710 arthroplasties. J Arthroplasty. 2015;30(8):1299-307. https://doi.org/1 0.1016/j.arth.2015.02.024.

23. Schairer WW, Vail TP, Bozic KJ. What are the rates and causes of hospital readmission after total knee arthroplasty? Clin Orthop Relat Res. 2014;472(1): 181-7. https://doi.org/10.1007/s11999-013-3030-7.

24. Bosco JA 3rd, Karkenny AJ, Hutzler LH, Slover JD, lorio R. Cost burden of 30day readmissions following Medicare total hip and knee arthroplasty. J Arthroplasty. 2014;29(5):903-5. https://doi.org/10.1016/j.arth.2013.11.006.

25. Belmont PJ Jr, Goodman GP, Waterman BR, Bader JO, Schoenfeld AJ. Thirtyday postoperative complications and mortality following total knee arthroplasty. Incidence and risk factors among a national sample of 15,321 patients. J Bone Joint Surg Am. 2014;96(1):20-6. https://doi.org/10.2106/JBJS. M.00018.

26. Pugely AJ, Callaghan JJ, Martin CT, Cram P, Gao Y. Incidence of and risk factors for 30-day readmission following elective primary total joint arthroplasty: analysis from the ACS-NSQIP. J Arthroplasty. 2013;28(9):1499504. https://doi.org/10.1016/j.arth.2013.06.032.

27. Zmistowski B, Restrepo C, Hess J, Adibi D, Cangoz S, Parvizi J. Unplanned readmission after total joint arthroplasty: rates, reasons, and risk factors. J Arthroplasty. 2013;28(9):1499-504.

28. Pugely AJ, Martin CT, Gao Y, Mendoza-Lattes S, Callaghan JJ. Differences in short-term complications between spinal and general anesthesia for primary total knee arthroplasty. J Bone Joint Surg Am. 2013;95(3):193-9. https://doi.org/10.2106/JBJS.K.01682.

29. Cram P, Lu X, Kates SL, Singh JA, Li Y, Wolf BR. Total knee arthroplasty volume, utilization, and outcomes among Medicare beneficiaries, 19912010. JAMA. 2012;308(12):1227-36. https://doi.org/10.1001/2012.jama.11153.

30. Cram P, Cai X, Lu X, Vaughan-Sarrazin MS, Miller BJ. Total knee arthroplasty outcomes in top-ranked and non-top-ranked orthopedic hospitals: an analysis of Medicare administrative data. Mayo Clin Proc. 2012;87(4):341-8. https://doi.org/10.1016/j.mayocp.2011.11.017.

31. Vorhies JS, Wang Y, Herndon J, Maloney WJ, Huddleston JI. Decreased length of stay after TKA is not associated with increased readmission rates in a national Medicare sample. Clin Orthop Relat Res. 2012;470(1):166-71. https://doi.org/10.1007/s11999-011-1957-0

32. Brown NM, Sheth NP, Davis K, Berend ME, Lombardi AV, Berend KR, et al. Total knee arthroplasty has higher postoperative morbidity than unicompartmental knee arthroplasty: a multicenter analysis. J Arthroplasty. 2012;27(8 Suppl):86-90. https://doi.org/10.1016/j.arth.2012.03.022.

33. Singh JA, Kwoh CK, Boudreau RM, Lee GC, Ibrahim SA. Hospital volume and surgical outcomes after elective hip/knee arthroplasty: a risk adjusted analysis of a large regional database. Arthritis Rheum. 2011;63(8):2531-9. https://doi.org/10.1002/art.30390.

34. Husni ME, Losina E, Fossel AH, Solomon DH, Mahomed NN, Katz JN. Decreasing medical complications for total knee arthroplasty: effect of critical pathways on outcomes. BMC Musculoskelet Disord. 2010;11(1):160. https://doi.org/10.1186/1471-2474-11-160.

35. Huddleston Jl, Maloney WJ, Wang Y, Verzier N, Hunt DR, Herndon JH. Adverse events after total knee arthroplasty: a national Medicare study. J Arthroplasty. 2009;24(6 Suppl):95-100. https:/doi.org/10.1016/j.arth.2009.05.001.

36. Pulido L, Parvizi J, Macgibeny M, Sharkey PF, Purtill JJ, Rothman RH, et al. In hospital complications after total joint arthroplasty. J Arthroplasty. 2008;23(6 Suppl 1):139-45. https://doi.org/10.1016/j.arth.2008.05.011.

37. Memtsoudis SG, Della Valle AG, Besculides MC, Gaber L, Sculco TP. Inhospital complications and mortality of unilateral, bilateral, and revision TKA: based on an estimate of 4,159,661 discharges. Clin Orthop Relat Res. 2008; 466(11):2617-27. https://doi.org/10.1007/s11999-008-0402-5. Epub 2008 Aug 14.

38. Katz JN, Bierbaum BE, Losina E. Case mix and outcomes of total knee replacement in Orthopaedic Specialty Hospitals. Med Care. 2008;46(5):47680. https://doi.org/10.1097/MLR.0b013e31816c43c8.

39. Borza T, Oerline MK, Skolarus TA, Norton EC, Ryan AM, Ellimoottil C, et al, Association of the Hospital Readmissions Reduction Program with surgical readmissions. JAMA Surg. 2018;153(3):243-50. https://doi.org/10.1001/jama surg.2017.4585.
40. Hannan EL, Zhong Y, Lahey SJ, Culliford AT, Gold JP, Smith CR, et al. 30-day readmissions after coronary artery bypass graft surgery in New York State. JACC Cardiovasc Interv. 2011;4(5):569-76. https://doi.org/10.1016/j.jcin.2011. 01.010.

41. National Clinical Guideline Centre - Acute and Chronic Conditions (UK). Venous Thromboembolism: Reducing the Risk of Venous Thromboembolism (Deep Vein Thrombosis and Pulmonary Embolism) in Patients Admitted to Hospital. London: Royal College of Physicians (UK); 2010.

42. Mula V, Parikh S, Suresh S, Bottle A, Loeffler M, Alam M. Venous thromboembolism rates after hip and knee arthroplasty and hip fractures. BMC Musculoskelet Disord. 2020;21(1):95. https://doi.org/10.1186/s12891-02 0-3100-4.

43. Gurusamy KS, Koti R, Wilson P, Davidson BR. Antibiotic prophylaxis for the prevention of methicillin-resistant Staphylococcus aureus (MRSA) related complications in surgical patients. Cochrane Database Syst Rev. 2013;8: CD010268. https://doi.org/10.1002/14651858.CD010268.pub2.

44. Peel T, Astbury S, Cheng AC. Multicentre randomised double-blind placebo controlled trial of combination vancomycin and cefazolin surgical antibiotic prophylaxis: the Australian surgical antibiotic prophylaxis (ASAP) trial. BMJ Open. 2019;9(11):e033718. https://doi.org/10.1136/bmjopen-2019-033718.

45. Richmond JC. CORR Insights ${ }^{\oplus}$ : Impact of preoperative MRSA screening and decolonization on hospital-acquired MRSA burden. Clin Orthop Relat Res. 2013;471(7):2372-3. https://doi.org/10.1007/s11999-013-2909-7 Epub 2013 May 21.

46. Moroski NM, Woolwine S, Schwarzkopf R. Is preoperative staphylococcal decolonization efficient in total joint arthroplasty. J Arthroplasty. 2015;30(3): 444-6. https://doi.org/10.1016/j.arth.2014.10.017 Epub 2014 Oct 23.

47. McHugh SM, Hill AD, Humphreys $H$. Laminar airflow and the prevention of surgical site infection. More harm than good? Surgeon. 2015;13(1):52-8. https://doi.org/10.1016/j.surge.2014.10.003 Epub 2014 Nov.

48. Popp W, Alefelder C, Bauer S, et al. Air quality in the operating room: surgical site infections, HVAC systems and discipline - position paper of the German Society of Hospital Hygiene (DGKH). GMS Hyg Infect Control. 2019; 14:Doc20. https://doi.org/10.3205/dgkh000335 eCollection 2019.

49. Dailey EA, Cizik A, Kasten J, Chapman JR, Lee MJ. Risk factors for readmission of orthopaedic surgical patients. J Bone Joint Surg Am. 2013; 95(11):1012-29. https://doi.org/10.2106/JBJS.K.01569.

50. Riley RD, Hayden JA, Steyerberg EW, et al. PROGRESS Group. Prognosis Research Strategy (PROGRESS) 2: prognostic factor research. PLoS Med. 2013;10(2):e1001380. https://doi.org/10.1371/journal.pmed.1001380.

51. Bedard NA, Pugely AJ, McHugh M, Lux N, Otero JE, Bozic KJ, et al. Analysis of outcomes after TKA: Do all databases produce similar findings? Clin Orthop Rel Res. 2018;476(1):52-63. https://doi.org/10.1007/s11999. 0000000000000011.

52. Postler A, Lützner C, Beyer F, Tille E, Lützner J. Analysis of total knee arthroplasty revision causes. BMC Musculoskelet Disord. 2018;19(1):55. https://doi.org/10.1186/s12891-018-1977-y.

53. Steinhaus ME, Christ AB, Cross MB. Total knee arthroplasty for knee osteoarthritis: support for a foregone conclusion? HSS J. 2017;13(2):207-10. https://doi.org/10.1007/s11420-017-9558-4.

54. Ferket BS, Feldman Z, Zhou J, Oei EH, Bierma-Zeinstra SM, Mazumdar M Impact of total knee replacement practice: cost effectiveness analysis of data from the Osteoarthritis Initiative. BMJ. 2017;356:j1131.

55. Lam V, Teutsch S, Fielding J. Hip and knee replacements: a neglected potential savings opportunity. JAMA. 2018;319(10):977-8. https://doi.org/10.1 001/jama.2018.2310.

\section{Publisher's Note}

Springer Nature remains neutral with regard to jurisdictional claims in published maps and institutional affiliations. 